4

\title{
The Matching Effect Between Coping Strategies and Construal Levels in Cause Marketing Communications
}

\author{
Mikyeung Bae \\ School of Media and Strategic Communications, Oklahoma State University, U.S.A. \\ $\triangle$ clara.bae@okstate.edu
}

\begin{abstract}
Given that the COVID-19 pandemic has had dramatic impact on consumer attitudes toward cause marketing communications, this study addresses the problem of how psychological stress influences consumers' prosocial behavior. Despite research suggesting that many aspects of consumer behavior may be understood in the context of consumer efforts to handle stress, cause marketing literature has not examined the role of stress and coping-based matching. Consequently, the aim of this study is to provide evidence that a match between individuals' coping and construal levels in advertisements drives greater persuasion. This study further addresses the mindset congruency effects on consumers' prosocial behavior occurs through response efficacy. Understanding how psychological stress influences consumers' prosocial behavior would help advertisers understand how they can encourage consumers to cope with specific types of stress by presenting them with more effective cause marketing campaign messages, resulting in purchasing products associated with social cause.
\end{abstract}

Keywords: psychological stress, coping strategy, construal level, cause marketing communications

\section{Introduction}

While brands seek to adopt the correct tone during the COVID-19 crisis, the outbreak has had a dramatic impact on consumer attitudes toward corporate social responsibility (CSR). A 
recent study conducted by Good.Must.Good (2020) found that more than the three-quarters of survey respondents believe how well a company has conducted in CSR during the pandemic will be an important factor in determining whether to support them in a postCOVID-19 world. It is hoped that COVID-19 pandemic will accelerate post-pandemic cause marketing advertising development in the long run as more firms realize that their long-term survival and development depends on achieving a delicate balance between profitability and harmony with its various stakeholders.

In contrast, a pessimistic view is that consumers are more likely to criticize brands that seem to be capitalizing on this opportunity, such as by using the global pandemic as the basis of any of their marketing campaigns (He and Harris 2020). A recent study found that 56\% believe too many brands use societal issues as marketing ploys to sell more of their products (Edelman.com 2020). Cause marketing campaigns, therefore, should ensure that a company's messaging is authentic by creating campaigns that aligns with its fundamental brand values, and uses a tone that consumers expect in the stressful pandemic situation.

\subsection{Stress, Coping Strategies, and Construal Level}

The cognitive theory of stress (Lazarus and Folkman 1984) proposes that people monitor their environment and undergo the appraisal process to interpret situations. When individuals identify an environmental event as harmful or threatening and do not have enough or adequate resources to adopt to such an event, they will perceive such an event as actually or potentially threatening or harmful (Dunlap et al. 1993; Lepore and Evans 1996). Lazarus and Folkman (1984) distinguish between two types of coping strategies: problem-focused and emotionfocused strategies. The former is defined by efforts to ameliorate the cause of stress, whereas the latter is defined by efforts to regulate one's emotional responses to the source of stress. A third coping strategy, meaning-focused coping, aims to change the evaluation of a stressful situation, focusing on strengths gained from life experience (Folkman and Moskowitz 2000; Park and Folkman 1997).

Construal level theory (CLT) (Trope and Liberman 2003) suggests that individuals may represent the same event or information at lower construal levels involving the feasibility consideration (e.g., means to an outcome) or higher construal levels emphasizing its desirability aspects (e.g., the end state's value) (Trope and Liberman 2003; Soderberg et al., 2015). Consumers' coping strategies have been examined as associating with consumers' construal levels, integrating coping theory with CLT (e.g., Han, Duhachek, and Agrawal 2016).

This study builds on previous studies suggesting that COVID-19-related stress might help advertisers understand the development of, and change in, a wide variety of consumer behaviors in cause marketing advertisements. It proposes that matching consumers' coping strategy induced by stresses with the construal level of the cause marketing campaign message will increase the persuasive power of campaigns. The premise on which the study proceeds is that the persuasive impact of a message featuring high or low-level construal depends on the coping strategies (e.g., problem-focused, emotion-focused, or meaning-focused) consumers employ.

Moreover, given that consumers are more willing to adopt a framed message when the frame fits their own mental states and representations (Lee and Aaker 2004), this study proposes that when correspondence between the consumers' coping strategies and the construal level at which the message is construed exists, the evaluation of cause marketing advertisements is more favorable than when such correspondence is absent.

\subsection{Self-Efficacy and Response Efficacy}

Coping literature has emphasized the role of individual resources in determining stressrelated outcomes: self-efficacy and response efficacy (Duhachek, Agrawal, and Han 2012; 
Han, Duhachek, and Agrawal 2016; Sujan et al. 1999). Self-efficacy refers to the belief that one can successfully execute the behaviors required to produce certain desired outcomes (Bandura 1997; 2012). Response efficacy refers to the belief that a certain behavior is effective in yielding a required outcome (Bandura 1997). It represents an individual's belief in the extent to which a prescribed behavior works (Moriarty 2009).

Coping-based matching may be driven by these two different types of efficacy. Understanding these types of efficacy will guide the understanding of a process mechanism underlying matching in that the match systematically changes individuals' beliefs regarding their ability to follow actions suggested in advertisements (i.e., self-efficacy) or changes their beliefs about the effectiveness of those actions (i.e., response efficacy). White, MacDonnell, and Dahl (2011) demonstrated that the effects of a match between message frame (i.e., gain or loss) and a construal level mindset (i.e., abstract or concrete) on recycling intentions are mediated by perceived self-efficacy along with processing fluency. Caldwell et al. (2010) found that when individuals engage in problem-focused coping, they feel greater self-efficacy for subsequent coping behaviors. Further, Han, Duhachek, and Agrawal (2016) found that a match between problem-focused coping and the low construal level of the health message led individuals to feel greater self-efficacy, while a match between emotion-focused coping and the high construal level of the health message led individuals to feel greater response-efficacy. Similarly, Keller (2006) found greater regulatory efficacy fit and higher intentions to perform the advocated behavior when a promotion focus is matched with self-efficacy (vs. response-efficacy) and when a prevention focus is matched with response efficacy (vs. self-efficacy). Given that promotion-focused coping aims to change the reality of stressful transactions by alleviating or eliminating the environmental stimuli, it is positively related to aspects of problemfocused coping (Folkman et al. 1986), which may correspond with low-level construals (Duhachek 2008). In contrast, prevention-focused coping aims to regulate an individual's emotional and meaning-making responses and to external demands (Carver, Scheier, and Weintraub 1989).

This study proposes that different types of coping (i.e., problem-focused, emotion-focused, and meaning-focused) and different types of efficacy (i.e., self-efficacy and response efficacy) together influence consumer behavior. Understanding the different types of efficacy will guide the analysis of the process mechanism underlying matching, where a match systematically changes individuals' beliefs in their ability to follow actions suggested in cause marketing advertisements (i.e., self-efficacy) or in the effectiveness of those actions (i.e., response efficacy).

\section{Online Experiment}

A 2 (construal level of cause marketing advertisement: high vs. low) $\times 3$ (coping: problemfocused vs. emotion-focused vs. meaning focused) between-subjects design was tested on campaign participation intention.

Participants $(N=580)$ were recruited through Amazon Mechanical Turk and received a \$1incentive for participation. Of these 580 participants, 13 were eliminated because of incomplete data. The final sample comprised 567 participants (65.4\% male). Their age ranged from 19 to 69 years, and the average age was 37.60 ( $\mathrm{SD}=11.08)$. The majority of the participants were white (57\%), followed by African Americans (31.9\%) and Asian (4.8\%). Participants' education levels varied from high school (10.2\%) to two-year college $(5.6 \%)$, four-year college (56.1\%), and graduate (28.1\%) degrees. Participants' demographic characteristics were not correlated with the dependent variable (all $p s>0.05$ ). 


\subsection{Stimuli Development}

More than 54 million people faced hunger because of COVID-19 in America (Feeding America 2020). Accordingly, a fight against hunger campaign was launched a charity organization called Move for Hunger. A dairy company PureDairy working with a nonprofit organization Move for Hunger was created as milk is known one of the most-requested items by food bank clients (Feeding America 2020).

Based on the aforementioned discussion, the brand webpage was created. A brand website is the most frequent medium for engaging in cause marketing advertisements; 98\% of Fortune 500 companies refer to social cause issues on their websites (Smith and Alexander 2013). Besides, $82 \%$ of consumers visit company websites before deciding to buy a product or service (Forbes, com 2016). Therefore, a brand's website can target the best consumers and influence their attitudes and intention to participate in the advertised cause marketing campaign.

Multiple operationalizations of the successfully employed constructs were initiated (Trope, Liberman, and Wakslak 2007). Specifically, the construal level (high vs. low) varied by the following: (a) using a headline that focused on either high-level end states of actions or lowlevel of the means; (b) using a subhead illustrating either high-level the why aspect or lowlevel of the means by which donations are implemented; (c) using a body text to describe benefits that emphasized high-level aspects of why one would join this cause campaign or the low-level means by which actions are accomplished by purchasing a product.

Problem-, emotion-, and meaning-focused coping were manipulated by adopting the method used by Miller, Kahn, and Luce (2008). All conditions have the same cover story describing the possible COVID-19-associated stress the participants might experience. Participants took part in the experiment online. After reading the cover story, participants indicated how much they felt stress. Participants' construal level was then measured. Each participant was randomly assigned to one of two cause campaigns (high-level construal message vs. lowlevel construal message). They then responded to questions regarding both their selfefficacy and response efficacy and campaign participation intentions.

\subsection{Measures}

\subsubsection{Construal Level}

Participants' construal levels were measured using the 25-item Behavior Identification Form (BIF) (Vallacher and Wegner 1987). For each question, participants read a statement of action (e.g., making a list), followed by two options describing the action regarding either why it is performed, which is consistent with higher-level construals (e.g., getting things organized), or how it is performed, which is consistent with lower-level construals (e.g., writing something down). Participants were then required to choose the description that best captured their view of the activity. Participants' responses were coded as 0 for choosing lower construal levels, and 1 for choosing higher construal levels, and summed to form a BIF score.

\subsubsection{Perceived Self-Efficacy}

Bandura introduced self-efficacy as a domain-specific construct. He sees self-efficacy as the perceived ability to perform concrete actions to achieve specific outcomes (Bandura 1997). Accordingly, perceived self-efficacy was measured using three items of the cause marketing domain adopted from White et al. (2011). Examples of the items are as follows: "I feel that by participating this cause marketing campaign, I can contribute in solving the hunger problem," "I feel that by participating in this campaign, I can help foster food security in this country," and "I believe that by participating this campaign, I can take care 
of people suffering from the hunger problem" $(1=$ strongly disagree, $7=$ strongly agree $)$ $(M=5.32, \mathrm{SD}=0.98, \alpha=0.83)$.

\subsubsection{Perceived Response Efficacy}

Perceived response efficacy was measured using three items adopted from Keller (2006). Participants rated whether they thought "joining this cause campaign can reduce the threat of hunger," "joining this campaign can prevent people from hunger," and "joining this campaign can bring hope to people in hunger" $(1=$ not at all, $7=$ a great deal $)(M=5.17$, $\mathrm{SD}=1.17, \alpha=0.74)$.

\subsubsection{Intention to Participation in The Campaign}

Campaign participation intentions were assessed using three items. These items include the following: "I would be willing to participate in this CRM campaign," "I would consider purchasing this product to provide help to the cause," and "I would likely contribute to this cause by getting involved in this CRM campaign" $(M=5.21, S D=1.29, \alpha=.87$ ) (Grau and Folse 2007).

Measures for potential confounds included issue involvement (Unimportant/Important, Irrelevant/Relevant, of no concern/Of concern, means nothing/Means a lot, Does not matter/Matters a great deal to me) $(\alpha=.89)$ (Maheswaran and Meyers-Levy 1990) and company/nonprofit organization familiarity (Not at all/Very much), which were not found as a significant covariate for main analyses.

\section{Results}

\subsection{Manipulation Checks}

Manipulation checks were tested using the questions to correspond to high versus low construal level used in the pretest. The results of the independent samples t-test demonstrated that participants in the high-level construal message condition perceived the campaign ad to be more abstract and focused on the why aspects of end state of action ( $M_{\text {high }}=5.17, \mathrm{SD}=$ $\left.1.01, M_{\text {low }}=4.85, \mathrm{SD}=1.14, t(565)=3.41, p<.001\right)$, while participants in the low-level condition perceived the campaign to be more concrete and featured the how-to aspects of the action $\left(M_{\text {low }}=5.33, \mathrm{SD}=0.93, M_{\text {high }}=4.78, \mathrm{SD}=1.23, t(565)=5.97, p<.001\right)$. The results indicate a successful manipulation of the construal level of the message.

It is also important to check whether the primed coping strategies varied as intended. Participants were asked to complete a modified version of the Ways of Coping Questionnaire (WOC; Folkman et al., 1994) including Planful Problem-Solving (7 items, such as "I made a plan of action and followed it"); Distancing (8 items, such as "refused to think about it too much"); and Positive Reappraisal (10 items, such as "tried to look on the bright of the things"). These specific forms of coping are good exemplars of problem-focused, emotion-focused, and meaning-focused coping. A one-way analysis of variance (ANOVA) and follow-up Bonferroni correction indicated that participants primed with problem-focused coping reported significantly higher score on the problem-focused coping scale $(M=5.95, \mathrm{SD}=0.85)$ than emotion-focused $(M=4.88, \mathrm{SD}=1.15)$ and meaning-focused coping $(M=5.15, \mathrm{SD}=$ 1.20 $)(F(2,564)=51.25, p<0.001)$. Participants primed with emotion-focused coping reported significantly higher score on the emotion-focused coping scale $(M=5.78, \mathrm{SD}=1.01)$ than problem-focused $(M=4.86, \mathrm{SD}=1.29)$ and meaning-focused coping $(M=5.01, \mathrm{SD}=$ 1.08) $(F(2,564)=34.72, p<0.001)$. Participants in a meaning-focused coping condition also rated significantly higher score on the meaning-focused coping scale $(M=5.85, \mathrm{SD}=0.89)$ than 
problem-focused $(M=4.79, \mathrm{SD}=1.30)$ and emotion-focused coping $(M=4.59, \mathrm{SD}=1.31)(F$ $(2,564)=60.51, p<0.001)$. The results indicate the primed coping strategies varied as intended.

Participants' stress was measured using the eight-item measure from the pretest (Durante and Laran, 2016). No significant differences in the stress levels among those who were in the problem-focused $(M=4.70, \mathrm{SD}=1.46)$, emotion-focused $(M=4.93, \mathrm{SD}=1.21)$, and meaning-focused coping conditions were reported $(M=4.81, \mathrm{SD}=1.23)(F(2,564)=1.47$, $p>0.05)$.

\subsection{Hypothesis Test}

Coping strategies and construal levels

The current study proposed that individuals primed to use problem-focused (vs. emotionfocused and meaning-focused) coping would analyze subsequent information at a lower level, while those primed to use emotion-focused and meaning-focused (vs. problem-focused) coping would construe following information at a higher level. An ANOVA on the construal level (i.e., BIF score) showed a significant effect of coping $(F(2,564)=98.82, p<.001)$. Planned contrasts using Bonferroni corrections showed that participants in the problemfocused coping condition scored significantly lower $\left(M_{\text {problem }}=13.08, \mathrm{SD}=3.54\right)$ than those in both the emotion-focused and meaning-focused coping condition $\left(M_{\text {meaning }}=17.84, \mathrm{SD}=\right.$ $\left.3.30, M_{\text {emotion }}=16.20, \mathrm{SD}=3.17 ; t(564)=13.25, p<.001\right)$. This result shows that those in the problem-focused coping condition (vs. emotion-focused and meaning-focused coping) are more likely to construe objects at lower levels, whereas those in the emotion-focused and meaning-focused coping conditions (vs. problem-focused coping) are more likely to construe objects at higher levels.

Table 1.

Levels of construal between problem-focused, emotion-focused, and meaning-focused coping

\begin{tabular}{ccccc}
\hline & Problem-focused & Emotion-focused & Meaning-focused & \\
$N=190$ & $N=190$ & $N=187$ & \\
\hline & $\mathrm{M}(\mathrm{SD})$ & $\mathrm{M}(\mathrm{SD})$ & $\mathrm{M}(\mathrm{SD})$ & $t(564)$ \\
Construal & $13.08(3.54)$ & $16.20(3.17)$ & $17.84(3.30)$ & $13.25^{* * *}$ \\
\hline
\end{tabular}

Note: ${ }^{* * * *} \mathrm{p}<.001$.

\subsection{Mindset Congruency Effect}

This study proposed that consumers primed to employ problem-focused coping would be more persuaded by cause marketing advertisements presented at lower (vs. higher) construal levels, while consumers primed to employ emotion-focused coping and meaning-focused coping would be more persuaded by cause marketing advertisement presented at higher (vs. lower) construal levels. A moderating analysis using a PROCESS macro (Hayes 2018) (model 1) was performed to test these hypotheses. The results revealed a significant interaction effect between high- or low-level construal message and coping strategy on campaign participation intention $(\beta=.59, S E=.13, t(563)=4.47, p<.001)$. A significant main effect of construal message type was found (coded 1 and 2 for low-level and high-level construal messages, respectively; $\beta=-1.14, S E=.28, t(563)=-4.04, p<.001)$. Coping strategy was also significant (coded 1 for problem-focused, 2 for emotion-focused, and 3 for meaning-focused; $\beta=-.73, S E=.21, t(563)=-3.56, p>.001)$. This approach includes procedures that compute a $95 \%$ confidence interval (CI) with a bootstrap analysis using a 10,000 sample. If a CI does not include zero, it indicates moderation. The results showed a significant conditional effect. Participants primed with problem-focused coping showed greater participation intention in response to a low-level message $(M=5.35)$ than a high-level message $(M=4.79)(\beta=.56$, 
$S E=0.16, t(563)=-3.29, p<.001$, confidence interval $[\mathrm{CI}]:-0.88$ to -0.22$)$. However, participants primed with emotion-focused coping did not show a significant difference in response to low-level and high-level construal messages $\left(M_{\text {low }}=5.20, M_{\text {high }}=5.23 ; \beta=.03\right.$, $S E=0.11, t(563)=.28, p>.05, \mathrm{CI}:-0.18$ to 0.24$)$. Participants primed with meaning-focused coping demonstrated greater campaign participation intention in response to a high-level message $(M=5.67)$ than a low-level abstract message $(M=5.05)(\beta=.62, S E=0.17, t(563)$ $=3.63, p<0.01$, CI: 0.28 to 0.95 ) (see Figure 1 ).

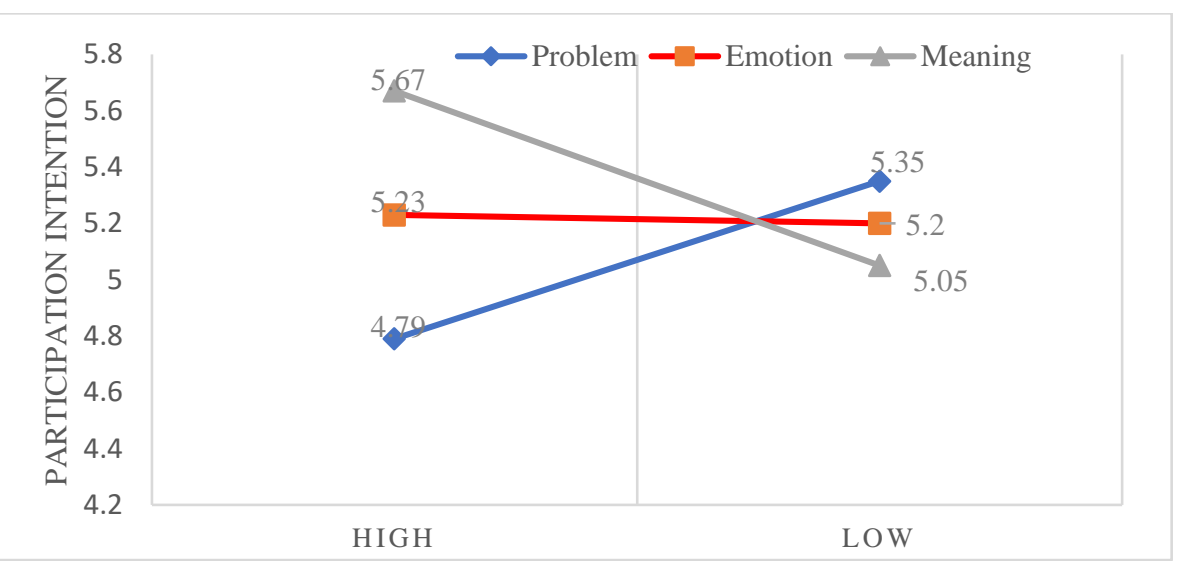

Figure 1. Interaction effect of construal message and coping style on intention

\subsection{Moderated Mediation Effect of Efficacies}

To examine whether two mediators, self-efficacy and response efficacy, mediated the interactive effect of construal messages and coping strategies on campaign participation intention, the moderated mediation analysis using model 8 of the PROCESS macro by Hayes (2018) was conducted. Table 2 presents the main results, which consist of three parts: mediator and dependent variable model, conditional direct effect analysis, and conditional indirect effect analysis. As can be seen from mediator and dependent variable model, only for response efficacy mediation model, effects of each antecedent variable on the subsequent variable was significant (construal message $\times$ coping strategy $\rightarrow$ response efficacy: $\beta=0.52$, $t(563)=4.36, p<.001$; response efficacy $\rightarrow$ participation intention: $\beta=0.74, t(563)=20.88$, $p<0.001)$. The results showed a significant indirect effect between construal level message and campaign participation intention among participants primed with a problem-focused coping strategy $(\beta=-0.32, \mathrm{CI}$ : -0.54 to -0.11$)$ and participants primed with meaning-focused coping ( $\beta=0.30, \mathrm{CI}: 0.12$ to 0.52 ). This indirect effect between construal level message and participation intention was not significant for participants primed with emotion-focused coping ( $\beta=.01, \mathrm{CI}:-0.14$ to 0.13 ). In contrast, the results did not support a mediating role of self-efficacy in the interactive effect of construal messages and coping strategies on campaign participation intention (message type $\times$ coping strategy $\rightarrow$ self-efficacy: $\beta=-0.07, t(563)=-$ $0.55, p>.05$; self-efficacy $\rightarrow$ participation intention: $\beta=0.01, t(563)=0.33, p>.05)$. A bootstrap analysis showed an insignificant indirect effect between construal messages and participation intention for participants primed with all three coping strategies $\left(\beta_{\text {problem }}=-0.00\right.$, CI: -0.02 to $0.01 ; \beta_{\text {emotion }}=-0.01, \mathrm{CI}:-0.01$ to $0.01 ; \beta_{\text {meaning }}=-0.01$, CI: -0.03 to 0.01 ). Essentially, unlike prediction, when exposed to a low construal level of message, participants primed to employ problem-focused coping were more likely to have response efficacy in forming participation intention and not through self-efficacy. In contrast, when exposed to a high construal level of campaign message, only those primed to employ meaning-focused coping underwent response efficacy in developing campaign participation intention, while those primed with emotion-focused coping did not. 
Table 2.

Conditional process analysis

\begin{tabular}{|c|c|c|c|c|}
\hline & $\beta$ & SE & $t$ & $\mathrm{CI}$ \\
\hline \multicolumn{5}{|l|}{ Mediator variable (self-efficacy) model } \\
\hline Constant & 5.61 & 0.41 & $13.66^{* * *}$ & $4.80-6.41$ \\
\hline Construal message (1) & 0.01 & 0.26 & 0.03 & $-0.50-0.52$ \\
\hline Coping strategy (2) & -0.19 & 0.19 & -1.02 & $-0.56-0.18$ \\
\hline $1 \times 2$ & -0.07 & 0.12 & -0.55 & $-0.30-0.17$ \\
\hline \multicolumn{5}{|l|}{$\begin{array}{l}\text { Mediator variable (response efficacy) } \\
\text { model }\end{array}$} \\
\hline Constant & 6.43 & 0.40 & $16.00^{* * * *}$ & $5.64-7.22$ \\
\hline Construal message (1) & 1.04 & 0.25 & $4.07^{* * *}$ & $0.54-1.54$ \\
\hline Coping strategy (2) & 0.62 & 0.18 & $3.34^{* * *}$ & $0.26-0.98$ \\
\hline $1 \times 2$ & 0.52 & 0.11 & $4.36^{* * *}$ & $0.28-0.74$ \\
\hline \multicolumn{5}{|l|}{ Dependent variable model } \\
\hline Constant & 1.82 & 0.43 & $4.23^{* * *}$ & $0.97-2.67$ \\
\hline Self-efficacy & 0.01 & 0.03 & 0.33 & $-0.05-0.07$ \\
\hline Response efficacy & 0.74 & 0.04 & $20.88^{* * *}$ & $0.67-0.80$ \\
\hline Construal message (1) & -0.37 & 0.21 & -1.75 & $-0.79-0.04$ \\
\hline Coping strategy (2) & -0.27 & 0.15 & -1.76 & $-0.57-0.03$ \\
\hline $1 \times 2$ & 0.20 & 0.09 & $2.07^{*}$ & $0.01-0.40$ \\
\hline \multicolumn{5}{|l|}{ Conditional direct effect } \\
\hline Problem-focused coping & -0.13 & 0.11 & -1.16 & $-0.35-0.09$ \\
\hline Emotion-focused coping & 0.04 & 0.08 & 0.45 & $-0.12-0.19$ \\
\hline Meaning-focused coping & 0.20 & 0.11 & 1.79 & $-0.02-0.42$ \\
\hline \multicolumn{5}{|l|}{$\begin{array}{l}\text { Conditional indirect effect } \\
\text { (Self-efficacy) }\end{array}$} \\
\hline Problem-focused coping & -0.00 & 0.01 & & $-0.02-0.01$ \\
\hline Emotion-focused coping & -0.01 & 0.00 & & $-0.01-0.01$ \\
\hline Meaning-focused coping & -0.01 & 0.00 & & $-0.03-0.01$ \\
\hline \multicolumn{5}{|l|}{$\begin{array}{l}\text { Conditional indirect effect } \\
\text { (Response-efficacy) }\end{array}$} \\
\hline Problem-focused coping & -0.32 & 0.10 & & $-0.54--0.11$ \\
\hline Emotion-focused coping & -0.01 & 0.07 & & $-0.15-0.13$ \\
\hline Meaning-focused coping & 0.30 & 0.09 & & $0.12-0.51$ \\
\hline \multicolumn{5}{|l|}{ Index of moderated mediation } \\
\hline Self-efficacy & -0.00 & 0.01 & & $-0.01-0.00$ \\
\hline Response efficacy & 0.38 & 0.09 & & $0.21-0.57$ \\
\hline
\end{tabular}

Note: $\mathrm{CI}=$ confidence interval, ${ }^{*} \mathrm{p}<.05,{ }^{* * *} \mathrm{p}<.001$.

\section{Discussion}

The first main finding of this study indicates that using problem-focused coping activates low construal-level mindsets, while the use of emotion-focused and meaning-focused coping elicits high construal-level mindsets. As the previous studies suggested, when individuals employ a problem-focused coping strategy, they might think about how to improve a stressful situation, planning actions on how to handle the source of the stress (Folkman 2010), which characterizes low-level construals. In contrast, when employing emotion-focused coping, 
individuals regulate their emotions by engaging in activities to take their minds off of a problem (Mathur, Moschis, and Lee 2008). Basically, they distance themselves from the stressor and do not focus on the potentially negative details about the source of stress (Ehrich and Irwin 2005), which characterizes high-level construals. When adapting a meaningfocused coping strategy, individuals tend to share a high-level abstract mindset that requires focus on the central, primary features guided by their broader values and that are more open to dealing with stressful situations (Wakslak and Trope 2009). Thus, high-level construal enabled individuals to reevaluate the threats of the event, which strengthened their ability to find positive meaning in traumatic experiences (Namkoong and Henderson 2015). This study provides additional evidence that the different coping strategies associated with different construal levels are used by individuals in stressful situations.

This study also found a mindset congruency effect in a stressful situation. Previous studies have agreed that a match of message frames with consumers' mindset leads to greater persuasion (Fujita et al. 2006; White, MacDonnell, and Dahl 2011; Labroo and Patrick 2009). The current study further found that a match between individuals' coping and construal levels in advertisements drove greater persuasion.

\section{Implications}

\subsection{Theoretical implication}

Cause marketing literature has not examined the role of stress and coping-based matching. To fill this gap, this study shows that a match between individuals' coping and construal level of the message increases persuasion. Basically, by suggesting that the persuasive impact of a message featuring a high- or low-level construal depends on coping strategies consumers employ, this study broadens the application of the cognitive theory of stress and CLT to the domain of cause marketing communications.

Moreover, the study enriches the coping literature by showing a deeper understanding of the mechanisms behind the mindset congruency effect. A considerable amount of research has demonstrated the effect of a match on persuasion and has identified a variety of mediating processes in these relationships (Lee, Keller, and Sternthal 2010; Mayer and Tormala 2010). This study identifies a novel process, building on the previous findings examining the mediating role of different efficacy types (Han, Duhachek, and Agrawal 2016; White, MacDonnell, and Dahl 2011). Previous studies have examined the role of efficacy in determining the use of either problem- or emotion-focused coping strategies (Lazarus and Folkman 1984; Sujan et al. 1999). However, scant research has examined the possibility that a particular coping strategy activates efficacy as a consequence. This study demonstrated the likelihood that the interactive effect of coping and the construal level activates efficacy as a consequence.

No study so far has examined the interactive effect of meaning-focused coping strategy and construal mindset, which may activate response efficacy, which would then predict campaign participation intention. More attention must be given to meaning-focused coping, as it appears useful approach for coping with stressful situations (Park and Folkman 1997; Park, Folkman, and Bostrom 2001). Previous research has shown that response efficacy mediated the interactive effect of coping and the construal level on persuasion only in emotion-focused conditions, while selfefficacy mediated the interactive effect of coping and the construal level on persuasion only in the problem-focused coping condition (Han, Duhachek, and Agrawal 2016). However, the study's findings suggest that the mindset congruency's effects on campaign participation intention occurred only through response efficacy. Therefore, the study contributes to persuasive communication literature by identifying new consequences of a match between coping and the 
construal level. Moreover, it demonstrates the mediating role of response efficacy in driving the effects of a match on persuasion, resulting from problem- and meaning-focused coping forms.

\subsection{Practical Implication}

Along with its theoretical implications, this study has important managerial implications. One key contribution of this research is that it identifies an actionable strategy for companies to improve the effectiveness of their communications in a cause marketing domain mired in COVID-19induced stress. More specifically, advertisers can mitigate the negative impact that stressful situations have on consumers' responses through using high-construal or low- construal messaging when communicating cause marketing information. Conveying cause marketing campaign information in a high-level abstract manner has been shown to increase consumers' behavioral intention as it is congruent with the high-level construal mindset resulting from employing a meaning-focused coping strategy. In contrast, delivering information in a low-level concrete manner has been found to increase behavioral intention, as it is congruent with the lowlevel construal mindset caused by employing a problem-focused coping strategy.

An additional practical implication of this study is in the finding that the mindset congruency increases campaign participation intention by increasing response efficacy. Response efficacy has particularly significant practical implications for a cause marketing campaigns given its ability to be developed within a message and the subsequent direct influence it has upon the message's effectiveness. Thus, advertisers can enhance the effectiveness of their cause marketing campaign appeals further by changing consumers' beliefs about the effectiveness of their actions. Advertisers should understand this unique efficacy process when they develop cause marketing campaign messages.

\section{References}

Baker, John P., and Howard Berenbaum. 2007. "Emotional approach and problem-focused coping: A comparison of potentially adaptive strategies." Cognition and Emotion 27 (1):95-118.

Bandura, Albert. 1997. "Self efficacy adn health behavior." In Cambridge handbook of psychology, health and medicine, edited by A. Baum, S. Newman, J. Weiman, R. West and C. McManus, 160-162. Cambridge: UK: Cambridge University Press.

Caldwell, Karen, Mandy Harrison, Marianne Adams, Rebecca H. Quin, and Jeffrey Greeson. 2010. "Developing mindfulness in college students through movement-based courses: Effects on self-regulatory self-efficacy, mood, stress, and sleep quality." Journal of American College Health 58 (5):433-442.

Carver, Charles S., Michael F. Scheier, and Jagdish Kumari Weintraub. 1989. "Assessing coping strategies: A theoretically based approach." Journal of Personality and Social Psychology 56 (2):267-283.

Duhachek, Adam, Nidhi Agrawal, and Dahee Han. 2012. "Guilt versus shame: Coping, fluency, and framing in the effectiveness of responsible drinking messages." Journal of Marketing Research 49 (6):928-941.

Duhachek, Adam . 2008. "Summing up the state of coping research." In Handbook of consumer psychology, edited by Haugtvedt Curt P. Herr Paul M. and Kards F. R. 10571077. New York: NY: Psychology Press.

Dunlap, Riley E., George H. Gallup Jr., and Alec M. Gallup. 1993. "Of global concern: Results of the health of the planet survey." Environment: Science and Policy for Sustainable Development 35 (9):7-39. 
Durante, Kristina M., and Juliano Laran. 2016. "The effect of stress on consumer saving and spending." Journal of Marketing Research 53 (5):814-818.

Edelman.com. 2020. "Edelman trust barometer special report." https://www.edelman.com/sites/g/files/aatuss191/files/201906/2019_edelman_trust_barometer_special_report_in_brands_we_trust.pdf.

Ehrich, Kristine R., and Julie R. Irwin. 2005. "Willful ignorance in the request for product attribute information." Journal of Marketing Research 42 (3):266-277.

Folkman, Susan, Richard S. Lazarus, Rand J. Gruen, and Anita DeLongis. 1986. "Appraisal, coping, health status, and psychological symptoms." Journal of Personality and Social Psychology 50 (3):517-579.

Folkman, Susan, and Judith Tedlie Moskowitz. 2000. "Stress, positive emotion, and coping." Current Directions in Psychological Science 9 (4):115-118.

Good.Must.Good. 2020. "Is Good Still Growing? Conscious Consumer Spending Index." Goodmustgrow.Com, accessed June 10. https://goodmustgrow.com/ccsi.php.

Guo, Mingzhu, Yiqun Gan, and Jing Tong. 2013. "The role of meaning-focused coping in significant loss." Anxiety, Stress \& Coping 26 (1):87-102.

Han, DaHee, Adam Duhachek, and Nidhi Agrawal. 2016. "Coping and construal level matching drives health message effectiveness via response efficacy or self-efficacy enhancement." Journal of Consumer Research 43 (3):429-447.

Keller, Punam A. 2006. "Regulatory focus and efficacy of health messages." Journal of Consumer Research 33 (June):109-114.

Labroo, Aparna A., and Vanessa M. Patrick. 2009. "Psychological distancing: Why happiness helps you see the big picture." Journal of Consumer Research 35 (5):800-809.

Lazarus, Richard S., and Susan Folkman. 1984. Stress, Appraisal, and Coping. New York, NY: Springer Publishing Company.

Lee, Angela Y. 2004. "Bringing the fram into focus: The influence of regulatory fit on processing fluency and persuasion." Journal of Personality and Social Psychology 86 (2):205-218.

Lee, Angela Y., Punam Anand Keller, and Brian Sternthal. 2010. "Value from regulatory construal fit: The persuasive impact of fit between consumer goals and message concreteness." Journal of Consumer Research 36 (5):735-747. doi: 10.1086/605591.

Lepore, Stephen J., and Gary W. Evans. 1996. "Coping with multiple stressors in the environment." In Handbook of coping: Theory, research, applications, edited by M. Zeidner and N. S. Endler, 350-377. New York: NY: John Wiley \& Sons.

Miller, Elizabeth Gelfand, Barbara E. Kahn, and Mary Frances Luce. 2008. "Consumer wait management strategies for negative service events: A coping approach." Journal of Consumer Research 34 (5):635-648.

Moriarty, Cortney Michelle. 2009. "Effects if self-efficacy and response efficacy in health news: Changing health attitudes and behavioral intention." International Communication Association, Chicago, IL.

Namkoong, Jae-Eun, and Marlone D. Henderson. 2015. "It's simple and I know it!: Abstract construals reduce causal uncertainty." Social Psychological and Personality Science 5 (3):352-359. 
Park, Crystal L., and Susan Folkman. 1997. "Meaning in the context of stress and coping." Review of General Psychology 1 (2):115-144.

Smith, Katherine Taken, and Julie J. Alexander. 2013. "Which CSR-related headings do Fortune 500 companies use on their websites?" Business Communication Quarterly 76 (2):155-171.

Soderberg, Courtney K., Shannon P. Callahan, Annie O. Kochersberger, Elinor Amit, and Alison Ledgerwood. 2015. "The effects of psychological distance on abstraction: Two meta-analyses." Psychological Bulletin 141 (3):525-548.

Sujan, Mita, Harish Sujan, James R. Bettman, and Theo M. M. Verhallen. 1999. "Sources of consumers' stress and their coping strategies." In E-European advances in consumer research edited by Bernard Dubois, Tina M. Lowrey and L. J. Shrum, 182-187. Provo: UT: Association for Consumer Research.

Trope, Yaacov and Nira Liberman. 2003. "Temporal construal." Psychological Review 110 (3):403-421.

Trope, Yaacov, Nira Liberman, and Cheryl Wakslak. 2007. "Construal levels and psychological distance: Effects on representation, prediction, evaluation, and behavior." Journal of Consumer Psychology 17 (2):83-95.

Updegraff, John A., and Shelley E. Taylor. 2000. "From vulnerability to growth: Positive and negative effects of stressful life events." In Loss and Trauma: General and Close Relationship Perspectives, edited by J. H. Harvey and E. D. Miller, 3-28. New York: NY: Brunner-Routledge.

Wakslak, Cheryl, and Yaacov Trope. 2009. "The effect of construal level on subjective probability estimates." Psychological Science 20 (1):52-58.

White, Katherine, Rhiannon MacDonnell, and Darren W. Dahl. 2011. "It's the mind-set that matters: The role of construal level and message framing in influencing consumer efficacy and conservation behaviors." Journal of Marketing Research 48 (3). doi: 10.1509/jmkr.48.3.472.

\section{Proud Pen}

(C) 2020 The Author(s). Licensee Proud Pen Limited. This chapter is distributed under the terms of the Creative Commons Attribution License (https://creativecommons.org/licenses/by/4.0/), which permits unrestricted use, distribution, and reproduction in any medium, provided the original work is properly cited.

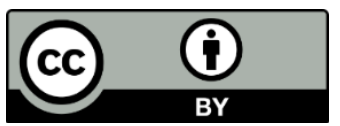

